\title{
Investigarea criminalistică a accidentelor de trafic rutier
}

\author{
Forensic investigation of road traffic accidents
}

\section{Petruţ Ciobanu ${ }^{1}$}

Rezumat: Cercetarea accidentelor de circulaţie este efectuată de aceleaşi organe care au sarcina de a strânge probele cu privire la existenţa infracţiunii, la identificarea autorului şi la stabilirea răspunderii sale, pentru a se constata dacă este sau nu cazul să se dispună trimiterea în judecată. Cercetarea accidentelor de circulaţie presupune stabilirea unor elemente sau clarificarea unor aspecte care pot să servească la conturarea naturii juridice a evenimentului, la determinarea răspunderii penale şi civile ce revine persoanei vinovate de producerea accidentului, prevenirea unor evenimente viitoare de aceeaşi natura. Activitatea de urmărire penală se desfaşoară sub supravegherea procurorului, care, după terminarea cercetării, va proceda la verificarea lucrărilor urmăririi penale, pentru a se putea pronunţa asupra legalităţii şi temeiniciei obţinerii, administrării probelor şi mijloacelor de proba.

Cuvinte-cheie: identificarea conducătorului autovehiculului, cercetarea la faţa locului, fotografie judiciara, urma de frânare, examinarea şi interpretarea urmelor, dispunerea, efectuarea şi valorificarea expertizelor criminalistice, reconstituire, confruntare.

\begin{abstract}
The investigation of traffic accidents is carried out by the same bodies that have the task of gathering evidence regarding the existence of the crime, identifying the perpetrator and establishing his responsibility, in order to ascertain whether or not it is necessary to order the prosecution. The investigation of traffic accidents involves establishing elements or clarifying aspects than can serve to outline the legal nature of the event, to determine the criminal and civil liability of the person responsible for the accident, preventing future events of the same nature. The criminal investigation activity is carried out under of supervision of the prosecutor, who after completing the investigation, will proceed to verify the criminal investigation works, in order to rule on the legality and validity of obtaining, administering evidence and means of proof.
\end{abstract}

Keywords: identification of the driver of the vehicle, on-site investigation, forensic photography, braking trace, examination and interpretation of traces, disposition, performance and capitalization of forensic expertise, reconstitution, confrontation.

${ }^{1}$ Conferențiar univ. dr., Facultatea de Drept, Universitatea din București, email: petrut.ciobanu@drept.unibuc.ro. 


\section{Petruț Ciobanu}

\section{Introducere}

Dezvoltarea transporturilor auto a determinat, în mod obiectiv, intensificarea eforturilor desfăşurate pe multiple planuri, în vederea asigurării siguranţei circulaţiei rutiere.

Aceste preocupări sunt necesare deoarece numărul de accidente este direct proporţional cu îmbunătăţirea performanţelor autovehiculelor, respectiv a vitezei de deplasare, element ce deţine prioritate in cauzele evenimentelor rutiere.

Gradul deosebit de periculozitate al accidentelor de circulaţie este determinat de faptul că aceste evenimente provoacă decese şi vătămări cu caracter violent, involuntar, la care se adaugă pagubele materiale considerabile.

Circulaţia pe drumurile publice a vehiculelor, pietonilor şi a celorlalte categorii de participanţi la trafic, drepturile, obligaţiile şi răspunderile care revin persoanelor fizice şi juridice, precum şi atribuţiile unor autorităţi ale administraţiei publice, instituţii şi organizaţii, sunt reglementate de dispoziţiile O.U.G. nr. 195/2002. Circulaţia autovehiculelor pe drumurile publice este reglementată prin H.G. nr. 1391/2006, modificat prin H.G. nr. 56/2007.

Activităţile sau acţiunile frecvente din cauza cărora se produc accidente grave sunt depăşirile neregulamentare, nerespectarea limitei de viteză, conducerea sub influenţa băuturilor alcoolice sau a drogurilor, comportamentul agresiv la volan, părăsirea locului accidentului fără aprobare.

Codul penal ${ }^{2}$ incriminează în Titlul VII Capitolul 2, art.334 -art.341, infracţiunile contra siguranţei circulaţiei pe drumurile publice, respectiv: punerea $\hat{i} n$ circulaţie sau conducerea unui vehicul neînmatriculat, conducerea unui vehicul fără permis de conducere, conducerea unui vehicul sub influenta alcoolului sau a altor substanţe, refuzul sau sustragerea de la prelevarea de mostre biologice, părăsirea locului accidentului ori modificarea sau ştergerea urmelor acestuia, împiedicarea sau îngreunarea circulaţiei pe drumurile publice, nerespectarea atribuţiilor privind verificarea tehnica ori efectuarea reparațiilor, efectuarea de lucrări neautorizate în zona drumului public.

În ceea ce priveşte noţiunea de accident de circulaţie, acesta poate fi definit drept un eveniment produs pe drumurile publice, constând în coliziunea a două sau mai multor vehicule, ori a unui vehicul cu un alt obstacol, lovirea sau călcarea pietonilor, având ca rezultat vătămarea integrităţii corporale ori moartea unei persoane, pagube materiale, precum şi stânjenirea circulaţiei ${ }^{3}$.

Controlul, supravegherea, răspunderea pentru luarea tuturor măsurilor de asigurare a securităţii circulaţiei revin organelor de poliţie.

Cercetarea accidentelor de circulaţie este efectuată de aceleaşi organe care au sarcina de a strânge probele cu privire la existenţa infracţiunii, la identificarea

${ }^{2}$ Legea nr. 286/2009 privind Codul penal, publicată în M.Of. nr. 510 din 24 iulie 2009, cu modificările și completările ulterioare

${ }^{3}$ C. Suciu, Criminalistica, Editura Didactică și Pedagogică, București, 1972, p. 640; G.Antoniu, C.Bulai, Gh.Chivulescu, Dicționar juridic penal, Editura Științifică și enciclopedică, București, 1976, p. 20. 
autorului şi la stabilirea răspunderii sale, pentru a se constata dacă este sau nu cazul să se dispună trimiterea în judecată.

Activitatea de urmărire penală se desfăşoară sub supravegherea procurorului, care, după terminarea cercetării, va proceda la verificarea lucrărilor urmăririi penale, pentru a se putea pronunţa asupra legalităţii şi temeiniciei obţinerii, administrării probelor şi mijloacelor de proba.

\section{Cauzele accidentelor de circulaţie}

Referitor la cauzele accidentelor de circulaţie există o bogată literatură de specialitate, întrucât există o preocupare constantă în vederea prevenirii şi combaterii acestor evenimente.

Cunoaşterea şi analiza cauzelor accidentelor de circulaţie a oferit specialiştilor în domeniu suficiente argumente pentru a afirma că aceste accidente nu sunt pe deplin accidentale ${ }^{4}$.

Se apreciază că accidentele sunt provocate de acţiunea a trei categorii importante de factori, aflaţi frecvent într-o anumită interdependenţă: factorul uman, tehnic şi rutier.

\subsection{Accidentele datorate factorului uman}

Accidentele datorate factorului uman deţin o pondere covârşitoare, reprezentând circa $90 \%$ din totalul evenimentelor de trafic, ceea ce a făcut să se afirme că "nu există accidente de automobile, ci de automobiliști".

Pe primele locuri în cauzele accidentelor provocate de factorii umani se situează, în ordine, excesul de viteză, neatenţia pietonilor, depăşirea neregulamentară şi conducerea sub influenţa băuturilor alcoolice sau a altor substanţe.

\subsection{Accidente datorate factorilor tehnici}

Accidentele datorate factorilor tehnici aparţinând autovehiculului sunt cele cauzate de defectarea sau funcţionarea defectuoasa a sistemelor de frânare, de direcţie, de rulare şi de semnalizare.

Defecţiunile tehnice trebuie uneori corelate cu influenţa factorului uman, în sensul lipsei de preocupare pentru întreţinerea şi revizia corespunzătoare a autovehiculelor.

\subsection{Accidentele datorate factorilor rutieri}

Accidentele datorate factorilor rutieri se referă la caracteristicile constructive şi de amenajare a căilor de comunicaţie (drumuri, şoşele, autostrăzi).

Străzile fără vizibilitate, podurile înguste, intersecţiile dintre arterele circulate intens, existenţa unor obstacole în apropierea părţii carosabile, reprezintă surse importante de pericol pentru deplasarea vehiculelor şi a pietonilor.

${ }^{4}$ Gh. Scripcaru, M. Terbancea, Patologie medico-legală, Editura Didactică și Pedagogică, București, 1978, pp. 218-219, Vl. Beliș, Medicină legală - curs pentru facultățile de drept, Editura Juridică, București, 2001, p. 150 și urm. 


\section{Principalele probleme care prezintă importanta în cazul cercetării accidentelor de trafic}

Cercetarea accidentelor de circulaţie presupune stabilirea unor elemente sau clarificarea unor aspecte care pot să servească la conturarea naturii juridice a evenimentului, la determinarea răspunderii penale şi civile ce revine persoanei vinovate de producerea accidentului, prevenirea unor evenimente viitoare de aceeaşi natura.

Împrejurările care trebuie stabilite în legătură cu producerea unui eveniment rutier sunt prezentate în continuare.

\subsection{Cauzele şi împrejurările în care s-a produs accidentul}

Referitor la cauze, investigaţia penală trebuie să stabilească factorii (umani, tehnici, rutieri) care au determinat sau favorizat evenimentul (rularea cu viteză mare pe un drum acoperit cu polei sau care nu prezintă vizibilitate).

Privitor la împrejurările accidentului, se vor stabili locul şi timpul producerii evenimentului, viteza şi direcţia de deplasare, starea drumului şi condiţiile meteorologice, starea tehnică a vehiculelor, avariile pe care le-au suferit, leziunile provocate victimelor ş.a. ${ }^{5}$.

\subsection{Regulile de circulaţie care au fost încălcate}

Regulile de circulaţie care au fost încălcate, cum ar fi, de exemplu, nerespectarea vitezei legale de circulaţie sau rularea cu o viteză necorespunzătoare în raport de condiţii concrete de trafic, nerespectarea normelor legale referitoare la prioritatea de trecere şi de depăşire, nerespectarea semnificaţiei semnalului de culoare roşie a semaforului electric sau la trecerea la nivel de cale ferată.

De asemenea, în cadrul cercetării penale se stabileşte dacă autorul accidentului a condus sub influenţa băuturilor alcoolice ori în stare de ebrietate, dacă autovehiculul prezintă defecţiuni tehnice la sistemul de direcţie şi de frânare, defecţiuni care trebuiau şi puteau fi sesizate.

\subsection{Persoanele răspunzătoare}

Persoanele răspunzătoare de producerea accidentului pot fi conducătorii autovehiculelor, pietonii, călătorii din mijloacele de transport în comun care nu respectă regulile de urcare şi de coborâre, şefii de garaje sau coloane care au permis plecarea în cursă a autovehiculelor cu defecţiuni tehnice.

Prezintă relevantă deosebita, în aceasta etapa, identificarea conducătorului autovehiculului care a părăsit locul accidentului. În acest sens, activităţile informativ-operative ale organelor de poliţie privind identificarea vehiculului şi a conducătorului respectiv, trebuie sa fie efectuate cu maximă operativitate.

${ }^{5}$ M. Le Clere, Manuel de police technique, Éditions Police Revue, Paris, 1974, pp. 7375; C. Suciu, supra cit., p. 642; A. Ciopraga și I. Iacobuță, Criminalistica, Editura Chemarea, Iași, 1997. 


\subsection{Consecinţele produse de accident}

Consecinţele produse de accident sunt importante pentru încadrarea juridică corecta a faptei penale comise.

Astfel, interesează pagubele materiale produse atât vehiculului care a provocat accidentul, cât şi celorlalte vehicule sau obiecte cu care a intrat în coliziune, numărul victimelor şi starea acestora.

În privinţa persoanei accidentate este necesar să se stabilească, în funcţie de calitatea pe care o avea în traficul rutier (pieton, pasager, conducător de vehicule cu tracţiune animală etc.), modul în care s-a comportat înaintea producerii evenimentului, starea în care se afla (de exemplu, mergea pe partea carosabilă, a traversat prin locuri nepermise fără să se asigure, era în stare de ebrietate).

\subsection{Posibilitatea de evitare a evenimentului}

În funcţie de circumstanţele în care s-a produs accidentul, este necesar să se clarifice dacă evenimentul putea fi evitat.

\subsection{Cercetarea altor fapte penale}

Cercetarea unui accident de circulaţie poate fi corelată cu cercetarea altor fapte penale: furt de maşină, utilizarea autoturismului pentru săvârşirea unui omor, tâlhării, furt, viol, ipoteze în care ne aflăm în situaţia concursului de infracţiuni.

\section{Particularităţi privind cercetarea la faţa locului a accidentelor de trafic rutier}

\subsection{Aspecte generale}

Cercetarea la faţa locului în cazul accidentelor de circulaţie reprezintă o importanta activitate de urmărire penală, cu caracter imediat şi necesar, de modul în care este efectuată depinzând direct soluţionarea cauzei ${ }^{6}$.

Cercetarea la faţa locului a accidentelor de circulaţie este orientată în două direcţii importante:

- Stabilirea împrejurărilor de loc, timp şi mod în care s-a produs accidentul.

- Descoperirea, fixarea şi ridicarea urmelor formate cu ocazia producerii accidentului.

Pe baza datelor obţinute prin cercetarea locului faptei, coroborate cu ascultarea persoanelor implicate în accident şi a martorilor oculari, organul de cercetare penală are posibilitatea să formuleze primele versiuni referitoare la natura evenimentului.

Cercetarea accidentelor de circulaţie se poate împărţi în două mari categorii:

${ }^{6}$ Vl. Stoica, Cercetarea accidentelor de circulație, în rev. PCC, nr. 3/1981, pp. 41-61, din fondul documentar al Compartimentului de criminalistică și de criminologie al Procuraturii Generale. 
a. Cercetarea accidentelor de circulaţie în care autorul a rămas la locul faptei, într-o situaţie asemănătoare aflându-se şi cel care s-a reîntors la faţa locului, după ce, de exemplu, a dus victima la spital.

b. Cercetarea accidentelor în care autorul a părăsit locul accidentului, ceea ce presupune ulterior identificarea autovehiculului şi a conducătorului acestuia.

Sarcinile lucrătorului de poliţie sosit primul la locul evenimentului sunt următoarele:

1. Acordarea primului ajutor victimelor, identificarea şi trimiterea lor de urgenţă la o instituţie medicala.

2. Asigurarea pazei locului şi luarea măsurilor necesare de conservare a urmelor accidentului.

3. Identificarea celorlalte persoane implicate în accident şi a martorilor oculari.

4. Raportarea evenimentului pentru ca, în funcţie de gravitatea accidentului, să se decidă dacă se impune ca cercetarea să fie efectuată de către o echipă specializată.

5. Luarea măsurilor de descongestionare, în măsura posibilităţilor, a circulaţiei, de înlăturare a unor pericole create de producerea accidentului.

\subsection{Pregătirea cercetării locului accidentului}

Cercetarea locului accidentului se face de către o echipă, în componenţa căreia vor intra, pe lângă lucrătorii serviciului circulaţiei, specialişti criminalişti şi eventual medicul legist, dacă accidentul a avut ca urmare moartea unor persoane rămase la faţa locului.

În situaţiile în care au fost implicate mai multe persoane, vehicule, victime sau au fost produse consecinţe deosebite, se impune participarea procurorului la efectuarea cercetării.

Pregătirea cercetării va consta în:

1. Verificarea şi completarea măsurilor luate iniţial de lucrătorul de poliţie sosit primul la locul faptei, îndeosebi de protejarea şi conservarea urmelor.

2. Delimitarea exactă a locului faptei, care nu se reduce numai la locul în care se află victima sau autovehiculul, acesta cuprinzând întreaga porţiune de drum şi terenul înconjurător al accidentului.

3. Obţinerea unor informaţii cu privire la împrejurările de producere a evenimentului.

4. Stabilirea sarcinilor şi a metodelor care vor fi aplicate pe parcursul cercetării, precum şi a locului de unde începe cercetarea.

\subsection{Efectuarea cercetării propriu-zise}

\subsubsection{Faza statică}

În faza statică a cercetării se procedează la examinarea şi fixarea aspectului de ansamblu a locului accidentului, la stabilirea poziţiei şi a raportului de distanţă dintre vehicule, dintre victimă şi vehicul, dintre acesta şi urmele descoperite. 
Vor fi efectuate fotografii judiciare operative de orientare, schiţă, măsurători fotografice, alte genuri de măsurători necesare redactării schiţei locului accidentului, o atenţie deosebită trebuind să fie acordată măsurării urmei de frânare.

Împrejurările negative ale accidentului vor fi lămurite pe parcursul investigaţiei criminalistice, nicidecum cu ocazia cercetării în faza statica. În aceasta faza, ele pot fi doar observate şi consemnate.

\subsubsection{Faza dinamică}

În faza dinamică se examinează amănunţit locului accidentului în vederea descoperirii, fixării, ridicării şi interpretării urmelor accidentului.

Examinarea se efectuează în funcţie de specificul fiecărei categorii de urme, pe baza unor metode tehnico-ştiinţifice proprii.

Astfel, într-un accident de circulaţie se întâlnesc urme de mai multe categorii:

e) urme ale sistemului de rulare ce se formează în raport de natura suprafeţei pe care se rulează, de modul de mişcare (rulare normală, frânare, derapare) şi tipul de bandaj sau şină;

f) urme ale unor părţi din caroserie sau diverse subansambluri (bară de protecţie, mască, far etc.) formate prin tamponarea sau lovirea victimei, a altor vehicule sau obstacole;

g) urme sub formă de resturi de obiecte şi materiale ca, de exemplu, cioburi de far şi de parbriz, resturi de vopsea, resturi metalice desprinse din caroserie, urme de benzină, ulei etc.;

h) urme biologice de natură umană îndeosebi urme de sânge, fire de păr, resturi de ţesut;

i) urme sub forma unor resturi de îmbrăcăminte sau a altor obiecte purtate de victimă asupra sa (ochelari, genţi , umbrelă etc.).

Urmele mijloacelor de transport descoperite pe corpul şi îmbrăcămintea victimei, în astfel de condiţii, permit identificarea obiectului creator din cauza fidelităţii cu care sunt redate o serie de caracteristici de individualizare.

\subsection{Examinarea şi interpretarea urmelor}

Prin examinarea şi interpretarea urmelor descoperite la locul accidentului este posibil să se rezolve mai multe probleme importante, încă din prima fază a cercetărilor, cum ar fi, de exemplu:

- stabilirea tipului de vehicul, posibilă prin studierea caracteristicilor constructive reflectate în urme (ampatament, ecartament, desen antiderapant etc. $)^{7}$;

- determinarea direcţiei de deplasare, pe baza urmelor desenului antiderapant ori a formei luate de picăturile de ulei, a altor lichide căzute în timpul mersului;

- stabilirea vitezei de circulaţie, prin măsurarea lungimii urmei de frânare, care este direct proporţională cu viteza vehiculului, dar şi în raport cu alţi factori.

${ }^{7}$ În acest sens, a se vedea E. Stancu, Investigarea științifică a infracțiunilor, partea I, Tipografia Universității Bucuresti, 1986, p. 240 și urm. 


\section{Petruț Ciobanu}

Pentru determinarea vitezei de rulare se recurge la mai multe formule matematice, în care sunt incluse diverse elemente, cum sunt, de exemplu, distanţa de frânare, coeficienţii de eficacitate a frânei şi de aderenţă a roţilor, durata întârzierilor fiziologice etc. ${ }^{8}$

\subsection{Fixarea rezultatelor cercetării}

Fixarea rezultatelor cercetării se face prin proces-verbal, fotografiere, schiţă. În situaţiile deosebite este preferabil să se recurgă la înregistrarea pe bandă videomagnetică sau înregistrare prin mijloace tehnice.

Examinarea îmbrăcămintei şi corpului victimei, a leziunilor pe care le prezintă aceasta, trebuie efectuată de către medicul legist potrivit regulilor aplicate în cazul oricărei morţi violente.

\section{Efectuarea altor acte de urmărire penală}

\subsection{Ascultarea martorilor}

Ascultarea martorilor oculari este de natură să servească la completarea sau clarificarea unor aspecte cu privire la împrejurările în care s-a produs accidentul, interesând viteza de circulaţie, comportamentul victimei, mai ales dacă acesta era un pieton, modul în care conducătorii autovehiculelor intrate în coliziune au respectat anumite reguli de circulaţie ş.a.

Organul de urmărire penală trebuie să ţină seama de condiţiile obiective şi subiective care ar fi putut influenţa procesul de percepţie cum sunt distanţa, caracterul iluminării, condiţiile meteorologice, rapiditatea cu care se petrec aceste evenimente, concentrarea atenţiei.

De asemenea, trebuie avută în vedere posibilitatea de apreciere a vitezei, diferită de la o persoană la alta, precum şi gradul în care aceste persoane cunosc regulile de circulaţie rutiera.

Sub raport tactic este important ca ascultarea sa fie efectuată cât mai repede posibil.

Ascultarea martorilor este deosebit de utilă în ipoteza părăsirii locului accidentului de către conducătorul auto, prin faptul că pot fi obţinute date de identificare a autovehiculului (număr de circulaţie, marcă, culoare etc.).

${ }^{8}$ V.Stoica, supra cit., pp. 46-49. Autorul menționează mai multe formule, cum ar fi, de pildă:

$V a=\frac{1,8}{K e}+g \max \cdot \cdot t 3 \cdot\left[\frac{26 g \cdot F(\text { red }) s(\text { pat })}{K e}\right\rfloor_{1 / 2,}$

$\mathrm{Va}=$ viteza inițială de aflat; $1,8=$ valoarea constantă

$\mathrm{Ke}=$ coeficientul eficacităţii frânelor;

t3 = timpul scurs de la începerea procesului de frânare;

$\mathrm{g}=$ gravitatea $(9,8 \mathrm{~m} / \mathrm{sec} 2)$;

$\mathrm{f}(\max )=$ valoarea mixtă a coeficientului de aderență;

$\mathrm{F}(\mathrm{red})=$ valoarea redusă a coeficientului de aderență;

$\mathrm{S}(\mathrm{pat})=$ spațiul de frânare cu roțile blocate (patinare). 


\subsection{Ascultarea persoanelor implicate în accident}

Ascultarea persoanelor implicate în accident, respectiv conducătorii autovehiculelor, victimele, va fi efectuată, de asemenea, cu maximă operativitate, declaraţiile acestora aducând date utile clarificării şi soluţionării cauzei.

În luarea declaraţiilor de la persoanele vătămate nu trebuie să se neglijeze starea de şoc în care se găsesc, stare ce este prezentă şi la cel vinovat de producerea accidentului.

\subsection{Dispunerea, efectuarea şi valorificarea constatărilor şi a expertizelor}

Dispunerea, efectuarea şi valorificarea constatărilor şi a expertizelor prezintă o deosebita importanţă în ceea ce priveşte aflarea adevărului judiciar.

În activitatea practică, se constată unele deficienţe, determinate fie de calitatea materialului pus la dispoziţia expertului, fie de formularea unor întrebări neclare sau referitoare la probleme care sunt de competenţa exclusivă a organului judiciar, singurul în măsură să le interpreteze şi să le clarifice din punct de vedere legal.

Astfel, expertiza tehnică se va limita la examinarea stării mecanice a autovehiculului, a sistemului de frânare, de direcţie, de semnalizare.

Se poate stabili dacă acesta a prezentat defecţiuni anterior producerii accidentului şi dacă ele puteau fi cauza evenimentului, se pot obţine date referitoare la caracteristicile tehnice ale autovehiculului sau drumului.

Expertiza criminalistică are ca obiective clarificarea unor împrejurări privind dinamica producerii accidentului, identificarea autovehiculului, a persoanei vinovate, îndeosebi în ipoteza părăsirii locului accidentului.

Pe baza caracteristicilor urmelor sistemului de frânare, a peliculelor de vopsea, a unor resturi desprinse din caroserie, a urmelor lăsate pe corpul victimei, poate fi identificat vehiculul antrenat în accident ${ }^{9}$.

Expertiza medico-legală poate stabili cauza şi natura morţii, mecanismul de formare a leziunilor, eventualele afecţiuni preexistente care au concurat la decesul persoanei ş.a.

O problemă importantă rezolvată prin expertiza medico-legală este aceea a determinării alcoolemiei, a stării sănătăţii conducătorului auto sau victimei, unele boli psihice, cardiovasculare, de nutriţie (diabetul), boli care pot provoca accidente de circulaţie.

${ }^{9}$ A se vedea, de exemplu, B. Bobaș, Cercetări privind unele elemente de stabilire a vitezelor în coleziunile autovehiculelor, în R.C.C.P. , nr. 3/2003, pp. 163-174; D. Sibian, Programul electronic de stabilitate ESP pentru autovehicule grele, în R.C.C.P. , nr. 3/2003, pp. 198-201; G. Bețiu, Coeficientul de aderență pneu-cale de rulare; factori care îl influențeazăa; valori uzuale, în R.C.C.P. , nr. 3/2003, pp. 149-156. 


\subsection{Efectuarea altor acte de urmărire penală}

Alte acte de urmărire penală (reconstituirea, percheziţia, confruntarea) sunt efectuate în funcţie de particularităţile fiecărui caz, în vederea aflării adevărului judiciar.

Reconstituirea este destinata determinării sau clarificării împrejurărilor care au favorizat accidentul (lipsa de vizibilitate, apariţia unor obstacole neaşteptate etc.) ori a condiţiilor în care a fost perceput de către martori.

Menţionăm faptul că nu pot fi reconstituite acele episoade ale accidentului care prezintă un anumit grad de pericol.

Percheziţia unui vehicul se efectuează, obligatoriu, în cazurile de părăsire a locului accidentului de către cel responsabil de producerea sa, pentru descoperirea autovehiculului, dar şi a unor mijloace materiale de probă.

În cazul accidentării de persoane, unii conducători auto părăsesc locul accidentului, parcând autovehiculul în alte locuri şi încearcă să înlăture urmele tipice de pe caroserie care rămân inevitabil în asemenea situaţii, mai ales urme de îmbrăcăminte şi urme biologice.

Percheziţia domiciliară se impune în majoritatea cazurilor de furturi de maşini.

Confruntarea serveşte la înlăturarea contradicţiilor din declaraţiile conducătorilor autovehiculelor implicate în accident, între aceştia şi martori.

Sub raport tactic criminalistic, organizarea confruntării trebuie efectuată în funcţie de cunoştinţele persoanelor confruntate privind posibilităţile reale de apreciere a vitezei, distanţei, stării drumului, comportamentului pietonilor, etc.

\section{Concluzii}

1. Cercetarea accidentelor de circulaţie presupune stabilirea unor elemente sau clarificarea unor aspecte care pot să servească la conturarea naturii juridice a evenimentului, la determinarea răspunderii penale şi civile ce revine persoanei vinovate de producerea accidentului, prevenirea unor evenimente viitoare de aceeaşi natura.

2. Identificarea conducătorului autovehiculului care a părăsit locul accidentului trebuie sa fie efectuată cu maximă operativitate prin activităţi informativ-operative ale organelor de poliţie.

3. Cercetarea unui accident de circulaţie poate fi corelată cu cercetarea altor fapte penale: furt de maşină, utilizarea autoturismului pentru săvârşirea unui omor, tâlhării, furt, viol, ipoteze în care ne aflăm în situaţia concursului de infracţiuni.

4. Dispunerea, efectuarea şi valorificarea constatărilor şi a expertizelor criminalistice prezintă o deosebita importanţă în ceea ce priveşte aflarea adevărului judiciar.

\section{Referinţe}

Antoniu G., Bulai C., Chivulescu Gh., Dicţionar juridic penal, Editura Ştiinţifică şi enciclopedică, Bucureşti, 1976

Beliş Vl., Medicină legală - curs pentru facultăţile de drept, Editura Juridică, Bucureşti, 2001 Beţiu G., Coeficientul de aderenţă pneu-cale de rulare; factori care îl influenţează; valori uzuale, în R.C.C.P. , nr. 3/2003, pp. 149-156 
Forensic investigation of road traffic accidents

Bobaş B., Cercetări privind unele elemente de stabilire a vitezelor în coleziunile autovehiculelor, în R.C.C.P. , nr. 3/2003, pp. 163-174

Ciopraga A., Iacobuţă I., Criminalistica, Editura Chemarea, Iaşi, 1997

Le Clere M., Manuel de police technique, Éditions Police Revue, Paris, 1974

Scripcaru Gh., Terbancea M., Patologie medico-legală, Editura Didactică şi Pedagogică, Bucureşti, 1978

Sibian D., Programul electronic de stabilitate ESP pentru autovehicule grele, în R.C.C.P. , nr. 3/2003, pp. 198-201

Stancu E., Investigarea ştiinţifică a infracţiunilor, partea I, Tipografia Universităţii Bucuresti, 1986

Stoica Vl., Cercetarea accidentelor de circulaţie, în rev. PCC, nr. 3/1981, pp. 41-61

Suciu C., Criminalistica, Editura Didactică şi Pedagogică, Bucureşti, 1972 